\title{
O USO DE PRÁTICAS PEDAGÓGICAS E INOVADORAS NAS AULAS DE GINÁSTICA PARA CRIANÇAS DE 4 E 5 ANOS DO CMEI "VIVER A INFÂNCIA", NA CIDADE DE GOIÂNIA/GO
}

\author{
Lara Gleib Marques Silva Araújo ${ }^{1}$ \\ João Henrique Suanno ${ }^{2}$
}

\begin{abstract}
Resumo: Esta pesquisa caracteriza-se como uma pesquisa qualitativa com características de estudo de caso, do CMEI Viver a Infância, em Goiânia. Esta pesquisa surgiu da seguinte questão: As aulas de ginástica ministradas no CMEI Viver a Infância, na cidade de Goiânia, utilizam práticas pedagógicas criativas? Assim, tem como objetivo geral: Avaliar-se as aulas de ginástica ministradas no CMEI Viver a Infância, na cidade de Goiânia, utilizam práticas pedagógicas criativas. A justificativa para tal estudo se deu a partir do interesse de saber como seria ensinar e facilitar o aprendizado para a populaçáo de 4 e 5 anos de idade, foco do projeto de extensão de Ginástica tendo esta pesquisadora como participadora voluntária, além do meu interesse de desvendar se os pesquisadores e pesquisadoras deste projeto utilizam da criatividade na elaboraçáo do seu plano semestral e se a esta faz parte do seu planejamento.
\end{abstract}

Palavras-chave: Práticas Pedagógicas. Criatividade. Inovação.

1 Graduada em Educação Física pela Universidade Estadual de Goiás - UEG. Professora do Colégio Militar do Estado de Goiás.

2 Pós-Doutor em Educação pela Universidade de Barcelona-UB/ES. Doutor em Educação pela Universidade Católica de Brasília-UCB/DF. Mestre Educação pela Universidad de La Habana/ Cuba revalidado pela Pontifícia Universidade Católica de Goiás-PUC/GO. Psicólogo-PUC/GO. Psicopedagogo-PUC/GO. Professor titular da Universidade Estadual de Goiás. Professor do Programa de Pós-Graduação Stricto Sensu Mestrado Interdisciplinar em Educação, Linguagem e Tecnologias - MIELT/UEG. Membro da Rede Internacional de Escolas Criativas-RIEC/UBES e RIEC-Brasil. Membro do Grupo de Pesquisa Ecologia dos Saberes e Transdisciplinaridade - ECOTRANSD/CNPq, coordenado pela Profa. Dra. Maria Cândida Moraes. Membro e pesquisador colaborador no projeto: Docência Transdisciplinar: a complexidade de uma prática a ser construída a partir de cenários e redes de aprendizagem integrada e ecoformadora-CNPq. Membro do Grupo de Pesquisa em Rede Internacional de Escolas Criativas-UFT/TO. Professor, Pesquisador, Palestrante e Conferencista. Investigador sobre Criatividade, Inovação, Escolas Criativas, Ecoformação, Transdisciplinaridade e outros. Autor e coautor de vários capítulos de livros e artigos publicados nacional e internacionalmente. 


\title{
THE USE OF PEDAGOGICAL AND INNOVATIVE PRACTICES IN GYMNASTICS FOR CHILDREN OF 4 AND 5 YEARS OF CMEI "LIVING CHILDHOOD”, IN THE CITY OF GOIÂNIA/GO
}

\begin{abstract}
This research is characterized as a qualitative research with characteristics of case study, of the CMEI Living the Childhood, in Goiânia. This research emerged from the following question: Do gymnastics classes taught at CMEI Viver a Infância, in the city of Goiânia, use creative pedagogical practices? Thus, it has as general objective: To evaluate the gymnastics classes taught at CMEI Viver a Infância, in the city of Goiânia, use creative pedagogical practices. The justification for this study came from the interest of knowing how it would be to teach and facilitate the learning for the population of 4 and 5 years of age, focus of the project of extension of Gymnastics having this researcher as voluntary participant, besides my interest of to discover if the researchers and researchers of this project use creativity in the preparation of their semiannual plan and if this is part of their planning.

Palavras-chave: Pedagogical Practices. Creativity. Innovation.
\end{abstract}

\section{INTRODUÇÃO}

Esta pesquisa caracteriza-se como uma pesquisa qualitativa com características de estudo de caso, do CMEI Viver a Infância, em Goiânia. Esta pesquisa surgiu da seguinte questão: As aulas de ginástica ministradas no CMEI Viver a Infância, na cidade de Goiânia, utilizam práticas pedagógicas criativas?

Assim, tem como objetivo geral: Avaliar-se as aulas de ginástica ministradas no CMEI Viver a Infância, na cidade de Goiânia, utilizam práticas pedagógicas criativas. A justificativa para tal estudo se deu a partir do interesse de saber como seria ensinar e facilitar o aprendizado para a população de 4 e 5 anos de idade, foco do projeto de extensão de Ginástica tendo esta pesquisadora como participadora voluntária, além do meu interesse de desvendar se os pesquisadores e pesquisadoras deste projeto utilizam da criatividade na elaboração do seu plano semestral e se a esta faz parte do seu planejamento.

A motivação para esta investigação foi a partir do momento da minha participação no projeto vinculado ao programa de bolsas de Iniciação Cientifica PBIC/UEG, junto ao projeto de pesquisa Criatividade e Ensino: Investigação sobre práticas criativas da escola do século XXI, e sobre o projeto de Iniciação Científica: $\mathrm{O}$ uso de práticas pedagógicas inovadoras e criativas no exercício docente em escolas públicas da cidade de Goiânia, e também pela participação ao evento que tive a oportunidade de atuar como monitora, do I Seminário da Rede Internacional de Escolas Criativas (I RIEC), onde surgiu a possibilidade para conhecer e me informar mais sobre as escolas criativas e as suas concepções, e como esta escola criativa influenciava nas aulas de Educação Física.

Com a inserção no Projeto de Iniciação Científica tive o interesse de analisar se as práticas do CMEI do Projeto de Extensão sobre Ginástica para Crianças, se este se utilizava da criatividade, mais primeiramente conversei com o meu professor, orientador, e membro da Rede Internacional de Escolas Criativas, para pensar esta possibilidade, e ele me apoiou e me incentivou. 
Conversando com a Professora Samanta Garcia de Souza, que foi minha professora no $2^{\circ}$ período do curso de Educação Física, com a disciplina de Ginástica I, ela me comunicou que estava realizando um projeto de extensão sobre Ginástica para Crianças, em um CMEI, perguntei se haveria formas criativas para ensinar os alunos ela me respondeu que havia, assim procurei possibilidade de participar desta pesquisa, e entrei no projeto como participante voluntária e, ao mesmo tempo, pesquisadora para o Projeto de Iniciação Científica.

Estes foram os dois caminhos me levaram para pesquisar como seria este diálogo, e a implantação e execução do potencial inovador e criativo das aulas de um programa de extensão de ginástica, que ocorreram no Centro Municipal de Educação Infantil "Viver a Infância”,na cidade de Goiânia, Estado de Goiás.

$\mathrm{Na}$ realização da pesquisa ocorreu uma investigação das ações, das práticas pedagógicas e dos projetos criativos e inovadores no para crianças de 4 e 5 anos no CMEI "Viver a Infância", na cidade de Goiânia, Estado de Goiás, ocorrerá a observação das propostas pedagógicas criativas e inovadoras. $\mathrm{Na}$ minha pesquisa irei utilizar os parâmetros da Rede Internacional de Escolas Criativas - RIEC e o VADECRIE, o professorado criativo, a visão transdisciplinar e transformadora e a avaliação formadora e transformadora, que é uma comunidade de ciência com consciência comprometida com o presente e o futuro da sociedade, e investiga práticas inovadoras e criativas na educação. A RIEC objetiva reconhecer os potenciais das escolas que tem uma visão transformadora, criativa e inovadora da educação e da sociedade.

\section{OBJETIVO}

Avaliar se as aulas de ginástica ministradas no CMEI Viver a Infância, na cidade de Goiânia/GO, utilizam práticas pedagógicas criativas. Este trabalho analisou o projeto de extensão da pesquisa intitulada como "Ginástica", desenvolvida no CMEI Viver a Infância.

\section{MÉTODO E METODOLOGIA}

A metodologia utilizada neste trabalho tem relação direta com o Materialismo Histórico Dialético, pois toda experiência ou relação do ser humano se encontra nos indivíduos cujo aquele que quando tem o elemento é necessário que haja a experiência esta experiência é aquela que aprendo coisas, ou algo, ou vem ou depende do modo da qual traz a interpretação materialista da experiência (LÊNIN, 1946).

A ideologia ela é representada por imagens, mitos, conceitos ou ideias, mais ela tem uma existência material onde surge uma relação entre as experiências reais e as experiências dos indivíduos e suas representações, o que impõe as relações reais e as relações vividas, onde é uma relação dos homens com o seu mundo para trazer condições de existências reais (ALTHUSSER, 1967). 
Algumas transformações são necessárias para que os seres humanos produzam a sua própria existência, onde criar uma capacidade de conhecimentos que vai modificando as relações societárias, conforme as suas necessidades, onde ocorra uma mudança que possa produzir a existência, e a ampliação das capacidades de produzir conhecimentos, que conforme o materialismo histórico dialético que permite ao ser humano a ir buscar novos caminhos ou resultados através da regressão ou progressão do objeto (SILVA, 2012).

De acordo com Vásquez, 2001, o materialismo histórico dialético busca como critério a prática enquanto, uma ação material, objetiva, transformadora que corresponda a sociedade, para que não seja só uma produção de uma realidade material, mas que seja uma criação do desenvolvimento incessante da realidade humana, que este possa corresponder ou não a um pensamento com a realidade, onde irá apresentar um caminho percorrido até os resultados a serem alcançados.

Campos (1997) o método materialista histórico-dialético caracteriza-se pelo movimento do pensamento através da materialidade histórica, sendo ela através da vida dos homens em sociedade e de tentar descobrir o seu movimento do pensamento e a forma de vida dos homens durante a história da humanidade.

Sendo assim Campos (1997) fala que o materialismo histórico dialético irá pensar em uma realidade que é necessário que se tenha a aceitação e contradição, do caminhar pela realidade e ver o que é possível apreender e o que dela é essencial. (Este movimentar do pensamento significa que é necessário refletir sobre a realidade partindo do empírico que seria a realidade dada, o real aparente, o objeto assim como ele se apresenta à primeira vista) e, por meio de abstrações (elaborações do pensamento, reflexões, teoria), chegar ao concreto: compreensão mais elaborada do que há de essencial no objeto, objeto síntese de múltiplas determinações, concreto pensado. Assim, a diferença entre o empírico (real aparente) e o concreto (real pensado) são as abstrações (reflexões) do pensamento que tornam mais completa a realidade observada.

O materialismo histórico dialético como o método, que é fundamental para a produção e análise do conhecimento científico por explicar as determinações sociais que estão colocadas nos interesse de classes, não pelas aparências fenomênicas ou pelas ideias, mas pela realidade como ela é (SILVA, 2012, p.34).

Esta pesquisa se caracteriza também por seguir a estratégia de uma pesquisa transdisciplinar, pois busca a religação de saber, e amplia o olhar sobre a realidade relacionando a o estudo sobre o concreto pensado com as possibilidades de emergências durante o processo e a relação entre esta e outras realidades. A pesquisa transdisciplinar busca a compreensão do ser humano em seu meio relacionando-o com as outras pessoas e com o mundo que a cerca e a ampliação dos níveis de percepção da realidade estudada, e valoriza o humano com suas percepções e considerações sobre o mundo em que vive.

Este trabalho foi realizado como forma de observar as práticas educacionais criativas e inovadoras do projeto de extensão do CMEI Viver a Infância na cidade de Goiânia-Go, com alunos de 4 e 5 anos que participaram do projeto de ginástica 
artística para crianças. São em média 16 a 22 alunos por sala, e analisei todas as aulas do período matutino que ocorre duas vezes por semana, na segunda-feira e na quinta-feira, no horário das 10 hsàs 11 hs.

Caracteriza-se por ser uma pesquisa participante, pois este estudo do projeto de extensão fui uma das estagiárias voluntarias do projeto, sob a metodologia do estudo de caso, pois investiga ações de um projeto de extensão específico, em uma escola específica. Tenho como intuito de avaliar os planos de aula e as práticas pedagógicas das estagiárias voluntárias aplicam esses planos. Mesmo sendo uma pesquisa da qual irei avaliar, é uma pesquisa da qual participo do projeto. Avaliarei também se os professores estão seguindo e ensinando os conteúdos dos planos de forma criativa, inovadora, humanizada, comprometida com a transformação do indivíduo, do meio e da sociedade.

Para esta pesquisa foram utilizados instrumentos para levantamento de dados como a entrevista semiestruturadas com a professora coordenadora do projeto de extensão, a análise documental dos planos de aula dos alunos voluntários do projeto, o questionário misto aplicado também aos alunos participantes do projeto de extensão e a observação das aulas práticas executadas pelos mesmos. Com esses instrumentos será realizada uma quadriangulação dos dados levantados para posterior análise e interpretação.

O intuito do projeto de extensão é ensinar os movimentos da ginástica, ministradas em um CMEI em Goiânia sobre as práticas de ginástica onde se utilizará da criatividade durante as aulas de educação física na Educação Infantil se está estava utilizando das formas criativas do processo de ensino e se este aluno estava passando pelo processo de aprendizagem para a sua formação como cidadão.

Para esta pesquisa utilizei o instrumento de valoração do desenvolvimento criativo das instituições de ensino (VADECRIE) os itens 2, 6 e o 9, na numeração original do VADECRIE, que no meu trabalho ficou numerado como os itens 1, 2 e 3 pois através dessas diretrizes escolhidas serviu para avaliar o desenvolvimento do processo criativo das instituições de ensino conforme o VADECRIE.

Todos os itens que foram escolhidos foram analisados de maneira coerente do que foi realizado no CMEI Viver a Infância, sendo assim os itens 2, 6 e 9 com relação do que foi vivido no CMEI trouxe uma grande semelhança com todos os 3 itens citados acima relacionado com o vivido no CMEI: As alunas que fazem parte do projeto, estagiárias voluntárias do projeto, cada um tinha a sua didática, e maneira de ensinar, sendo assim sempre combinando e refletindo em algo novo que poderia ser feito, conectava sempre os jeitos que já foram passados e com os que iriam transmitir para os alunos, sempre inovando e criando para ensinar os conteúdos da ginástica.

O item 2 do VADECRIE, que ao inverter para o meu trabalho ficou o item 1 , irá falar sobre o Professor Criativo/Formador Criativo: Um professor que ensina, aprende, inspira, constrói junto com os alunos, proporcionando uma ampliação do repertório de vários conhecimentos para atingir o alvo desejado, promovendo em seus alunos a aprendizagem, a independência, a flexibilidade proporcionando 
uma facilidade na complexidade e compreensão com um ensino criativo e transdisciplinar.

O item 6 do VADECRIE, que ao inverter para o meu trabalho ficou o item 3, irá falar sobre a Visão Transdisciplinar e Transformadora: Valorizando atitudes, comportamentos, valores e os conhecimentos dos alunos de uma forma transformadora. Dando grande importante as experiências com valores educativos que melhoram no desenvolvimento humano de uma maneira ampliada com uma expansão da consciência, em diversas matérias, olhares e contextualização do processo, da compreensão do ser, da vida, da cultura, em suas relações e interrelações. Onde a transdisciplinaridade não é apenas um mero conhecimento da realidade, mas, como criatividade, evidenciada na atitude.

O item 9 do VADECRIE, que ao inverter para o meu trabalho ficou o item 3, que irá falar sobre Transformar Avaliação e Formação: Os indivíduos avaliados são fortalecidos na sua aprendizagem através da reflexão e consciência dos processos e realizações. A avaliação é uma oportunidade para a análise, avaliação e reconhecimento de potenciais, talentos e realizações. A avaliação é em sentido criativo com vários critérios entre eles (adequação, relevância, valor, eficácia, eficiência, eficácia, ...) refletem o sentido de uma avaliação transdisciplinar. Essa diversidade pode ser considerada como a co-avaliação e grupo ou avaliação coletiva e não apenas o modelo individual.

Assim como o exposto acerca dos indicadores do instrumento utilizado, o VADECRIE, o professorado criativo, a visão transdisciplinar e transformadora e a avaliação formadora e transformadora percebe-se que quando se fala em criatividade, todos eles possuem uma relação com o pensamento voltado para as experiências da vida dos indivíduos de maneira global e sua vivência nos diversos meios onde haja convivência com outrem, no caso desta investigação, no CMEI Viver a Infância, na cidade de Goiânia. Aqui, há a característica de interação entre aqueles que sabem um pouco mais com aqueles que ainda estão em processo de construção do conhecimento e, por enquanto, não estão assim construídos e os indivíduos mais experientes também são capazes de aprender na interação, principalmente quando esta favorece e privilegia a criatividade por meio do pensar, do falar e do agir.

$\mathrm{Na}$ transdisciplinaridade não existem fronteiras entre as disciplinas e, para além delas, se preocupa com valores educativos que melhoram no desenvolvimento humano de uma maneira geral com uma expansão da consciência. Isso foi percebido na presente pesquisa quando o professorado possui uma visão ampla do que é seu exercício de mediar a aprendizagem dos alunos e os avalia para além da aprendizagem dos conteúdos. Na avaliação irá auxiliar a medir e analisar a formação da qualidade do aprendizado socializado nas aulas para os alunos, com a utilização de uma abordagem formativa e transformadora para analisar de uma forma mais segura. 


\section{RESULTADOS E DISCUSSÓES}

$\mathrm{Na}$ nossa pesquisa, foram entrevistadas 4 pessoas, sendo uma a coordenadora do CMEI, Viver a Infância, a coordenadora do projeto de extensão de ginástica, da qual essa é uma das professoras doutorando da Universidade Estadual de Goiás, e duas estagiárias voluntarias, que são acadêmicas da Universidade Estadual de Goiás a ESEFFEGO, e nas salas que foram destinadas ao projeto era em média de 15 a 18 alunos.

Para a análise de dados, foram pesquisados os seguintes instrumentos para levantamento o de dados como a entrevista semiestruturadas com a professora coordenadora do projeto de extensão, o questionário misto aplicado também as estagiárias voluntárias do projeto de extensão,a análise documental dos planos de aula dos alunos estagiários voluntários do projeto, e a observação das aulas práticas executadas pelos mesmos. Com esses instrumentos será realizada uma quadriangulação e realizei uma relação das diretrizes do VADECRIE em relação com o projeto para a análise e interpretação.

Apesar da realização do projeto de ginástica no CMEI, ter sido realizado com grande sucesso, deste projeto surgiu várias pesquisas e indagações para serem utilizadas em artigos e em monografias de universidades como a Universidade Estadual de Goiás, conforme a realização do projeto como foi o processo de aceitação da instituição em relação ao projeto.

Para a realização do Projeto a instituição nos recebeu com o total de disponibilidade, e esta instituição esteve disposta para ajudar e participar de maneira ativa do projeto a ser executado, onde também a entrevistada percebeu que está instituição tem um cuidado muito grande com os seus alunos, e sentimos uma segurança muito grande no local para a realização do projeto de ginástica e para a Pesquisa para o Projeto de Iniciação Científico.

\section{CONSIDERAÇÓES FINAIS}

Podemos concluir então que este projeto de extensão a partir de um olhar transdisciplinar, baseado na percepção em relação aos professores, em relação à visão transdisciplinar e transformadora, e em relação a avaliação formadora e transformadora possui ações pedagógicas criativas que vão para além dos conteúdo ministrados possibilitando que os envolvidos do projeto tanto alunos da instituição quanto, os participantes do projeto se transformam positivamente nas relações estabelecidas entre todos, já que qualquer relação estabelecidas entre as pessoas nos possibilita a repensar nossas ações e a nos melhorar enquanto seres humanos.

A criatividade, expressão e adaptação constituem a base para a atividade motora, realizada no sentido do movimento, pois cada indivíduo dará mais importância á vivência e experiência de si própria, as condições individuais e em conjunto proporcionará várias possibilidades de adaptação e opções a criatividade.

Foi utilizado como instrumentos de coleta questionários construídos com questões relacionadas ao projeto de extensão de ginástica para crianças, sendo este 
categorizado em identificação do pesquisado, e saber o objetivo analisar e investigar, para o Projeto de Iniciação Científica sobre: $\mathrm{O}$ uso de práticas pedagógicas Inovadoras e Criativas no exercício docente em escolas públicas dá cidade de Goiânia, e que nas aulas ministradas de Ginástica no CMEI Viver a Infância, pelo projeto de extensão de ginástica artística para crianças, da Universidade Estadual de Goiás - Eseffego no Campus Goiânia, se este utilizou em suas aulas as práticas pedagógicas, inovadoras e criativas. E chegou-se a conclusão que os resultados encontrados indicaram que a prática de ginástica proposta para as crianças influenciou positivamente o desenvolvimento da criatividade nas crianças e nos estagiários participantes, colaboraram para o seu desenvolvimento pessoal, as relações interpessoais entre outras.

\section{AGRADECIMENTOS}

À Universidade Estadual de Goiás - UEG, minha universidade, e à PróReitoria de Pesquisa - PRP, pelo apoio recebido com o programa BIC/UEG Bolsas de Iniciação Científica da UEG, que me oportunizaram o ingresso ao movimento da investigação científica por meio do meu orientador, com atividades que me fizeram entender e me encantar pelo universo da pesquisa.

Ao meu orientador Prof. Dr. João Henrique Suanno por tamanha dedicação, paciência para me orientar no presente estudo e por me deixar fazer parte do seu projeto de Iniciação Científica, me encorajando e sempre torcendo por mim, me dando a maior força no meio acadêmico, sempre falando "Lara olha esse evento vê se tem como você ir, vai ser muito importante para o seu currículo", me deu incentivo a participar de vários eventos, congressos, simpósios, projetos de extensões e sempre me ajudando a procurar evoluir.

A professora Samanta Garcia Souza, que permitiu pesquisar e participar do seu projeto de extensão de Ginástica no CMEI Viver a Infância em Goiânia Goiás, e por me ajudar do inicio ao fim. E não poderia deixa de agradecer aos professores (as) Conceição Vieira, por me deixar fazer parte do seu projeto de extensão de Yoga para Idosos, Renato Coelho por me permitir fazer parte do seu projeto de extensão do LABBRINC, Laboratório de Jogos e Brincadeiras, Gleyson Batista por me deixar participar do seu projeto de Paralímpicos para o Futuro: Atletismo. Obrigada de coração pela cumplicidade e ajuda de cada um de vocês.

Aos alunos do CMEI Viver a Infância, na cidade de Goiânia-GO, pela interação facilitada, pela convivência com a inocência da infância e pelas participações tão dedicadas às atividades propostas a eles.

Meu muito obrigada à todos...

\section{REFERÊNCIAS}

ALENCAR, E.M.L.S.; MARTINEZ, Albertina Mitjáns. Barreiras à expressão da criatividade entre profissionais brasileiros, cubanos e portugueses, Universidade Católica de Brasília, Universidade de Havana, Cuba, 1996.

ALTHUSSER, L. Análise crítica da teoria marxista. Rio de Janeiro: Zahar Editores, 1967. 
ALVES, Denilce de Castro et al. Interdisciplinaridade e a Formação do Professor, Monografia apresentada no Centro Universitário de Brasília - UniCEUB, 2006.

ANJOS, Maylta Brandão dos Anjos, Interdisciplinaridade na condução docente: Impressões a partir da vivência. IN: PINHO, Maria José de. Livro Com Complexidade, interdisciplinaridade e transdisciplinaridade na educação superior / Maria José de Pinho, Marilza Vanessa Rosa Suanno, João Henrique Suanno e Elzimar Pereira Nascimento Ferraz (orgs.). - Goiânia: / Editora Espaço Acadêmico, 2015.

AYOUB, Eliana. A Ginástica geral no contexto escolar. Campinas, SP: Tese (Doutorado) - Universidade Estadual de Campinas, Faculdade de Educação Física, 1998.

CAMPOS, Marília Freitas Pires D., O materialismo histórico-dialético e a educação, Campus de Botucatu, 1997.

LÊNIN, V. I. Materialismo e Empirocriticismo. Notas e Críticas Sobre uma Filosofia Reacionária. Editorial Calvino Ltda, Rio, 1946.

LIBANEO, J. C. Democratização da escola pública: a pedagogia crítico-social dos conteúdos. São Paulo: Loyola, 1985.

MATÍNEZ, Albertina Mitjáns. A criatividade na escola: três direções de trabalho. Linhas Críticas 8.15 (2002): 189-206.

MICARELLO, HAL da S.; DRAGO, Rogério. Concepções de infância e educação infantil: um universo a conhecer. Profissionais de educação infantil: gestão e formação São Paulo: Ática, p. 132-139, 2005.

MONTESSORI, Maria. Formação do homem. Tradução de Hauptmann e Eunice Arroxelas. Rio de Janeiro: Portugália Editora, 1950.

MOURA, Iarla Danielle de., IBIAPINA, Ivana Maria Lopes de Melo. Práticas pedagógicas criativas: possibilidades de formar sujeitos críticos - reflexivos. Campina Grande, REALIZE Editora, 2012.

OLIVEIRA, Nara Rejane Cruz de. Ginástica para todos: Perspectivas no contexto do lazer. Revista Mackenzie de Educação Física e Esporte V. 6. São Paulo (SP), 2007.

SILVA, Ivson Conceição, $\mathbf{O}$ materialismo histórico dialético e as mediações necessárias para análise da produção do conhecimento em educação física, esporte, e lazer, LEPEL/ FACED/UFBA. Anais Eletrônico - IV EPISTED Seminário de Epistemologia e Teorias da Educação. vol.1. No.1. dezembro de 2012. Faculdade de Educação/Unicamp

STÀLIN, J. V. Sobre o Materialismo Dialético e o Materialismo Histórico. Edições Horizonte, Rio, 1945.

TRIVIÑOS, A. N. S. Introdução à pesquisa em ciências sociais: a pesquisa qualitativa em educação. São Paulo: Atlas, 1987.

VOLPE, Medi Ann. Immanuel Kant (1724-1804). The Student's Companion to the Theologians, p. 287-289.

YOUNG, Michael. O futuro da educação em uma sociedade do conhecimento: a defesa radical de um currículo disciplinar. Cadernos de Educação, n. 38, 2011. 